\title{
Cigarette Smoking and Abstinence: Comparative Effects Upon Cognitive Task Performance and Mood State over 24 Hours
}

\author{
A. C. PARROTT ${ }^{1}$, N. J. GARNHAM ${ }^{1}$, K. WESNES ${ }^{2}$ and C. PINCOCK ${ }^{2}$ \\ 'Department of Psychology, University of East London, Romford Road, London E15 4LZ, UK; \\ ${ }^{2}$ Cognitive Drug Research, Priory Court, Beech Hill, Reading RG7 3EG, UK
}

Twenty regular smokers were assessed over 24-h of normal cigarette smoking, and an equivalent period of abstinence. In both conditions, a non-deprived baseline was followed by performance tests 2,6 and $24 \mathrm{~h}$ later, while subjective feelings were assessed every $2 \mathrm{~h}$. Compared to normal smoking, abstinence led to reduced heart rate, worse task performance, feelings of depression, stress, irritability, restlessness, poor concentration, and urges to smoke. Letter cancellation and number vigilance task performance were significantly poorer after 2 and $6 \mathrm{~h}$ of abstinence. Subjective feeling states were significantly worse after $4 \mathrm{~h}$ of abstinence, and became increasingly impaired over the rest of the day. However many abstinence symptoms (except heart rate), were reduced in severity at the 24-h session, held on the morning of the following day. This suggests that many of the psychological effects of smoking abstinence, may build-up afresh each day.

KEY WORDS - nicotine; tobacco; smoking; abstinence; withdrawal; mood; stress; irritability; performance; cognition; attention

\section{INTRODUCTION}

When regular smokers abstain from smoking, they typically report a range of subjective abstinence symptoms: irritability, poor concentration, restlessness, hunger, and cigarette craving (Shiffman and Jarvik, 1976; Stitzer and Gross, 1988; West and Russell, 1988; West et al., 1989; Hughes et al., 1990). The consistency of findings across studies, shows that the range of smoking withdrawal symptoms is well documented (West et al., 1989). However, most of these studies have measured withdrawal symptoms at only one or two time points, allowing West et al. (1989, p. 143) to conclude: 'There is little data on the time course of nicotine withdrawal symptoms'. More recently, Hughes (1992) measured withdrawal symptoms between 2 to 180 days post-cessation. The most severe abstinence symptoms were reported at the initial 2-day session, which raises the question of when they first develop during this initial period of abstinence. This is the central aim of the present study.

Similar questions can be raised with respect to objective task performance. Many studies have found higher levels of task performance in active smokers, compared to deprived smokers (Williams, 1980; Wesnes and Warburton, 1983; Hasenfrantz et al., 1989; Parrott and Roberts, 1991). Performance improvements in deprived smokers, have been empirically demonstrated after just one or two inhalations (Revell, 1988). In contrast, there is little information on the time course of performance changes during nicotine depletion. Foulds (1994) noted: 'I am not aware of a single placebo-controlled study looking at the time-course of cognitive performance changes following nicotine abstinence'. The other aim of the present study was therefore to measure cognitive task performance, over $24 \mathrm{~h}$ of smoking abstinence. However $24 \mathrm{~h}$ generally covers both sleep and waking, and the present study only sampled mood and performance during waking (it comprised a diurnal rather than circadian study (Folkard, 1983). Moods were assessed at baseline (around $10 \mathrm{am}$ ), then every $2 \mathrm{~h}$ until $12 \mathrm{~h}$ postbaseline (late evening), then finally again after $24 \mathrm{~h}$ (the following morning). Cognitive task performance was assessed at four test sessions: baseline, $2 \mathrm{~h}$ post-baseline (late morning), $6 \mathrm{~h}$ post-baseline

CCC 0885-6222/96/050391-10

(C) 1996 by John Wiley \& Sons, Ltd. 
(late afternoon), then after $24 \mathrm{~h}$ (following morning). The parallel use of subjective and objective measures, also allowed their time courses to be directly compared.

\section{METHOD}

\section{Subjects}

Twenty regular cigarette smokers (10 male, 10 female) agreed to participate in the study. The aims and objectives of the investigation and all subject requirements, were fully explained beforehand, while subjects were paid $£ 20$ on successful completion. Criteria for inclusion were: consumption of +10 cigarettes/day for at least 1 year $(+18.6 \pm 8.6$ cigarettes/day), and +18 years of age $(22.9 \pm 5.5$ years).

\section{Smoking and abstinence conditions}

In the smoking condition, subjects condition were asked to smoke normally. In the deprivation condition, subjects were required to abstain from smoking for $24 \mathrm{~h}$. In both conditions, subjects were asked to smoke one cigarette during the $15 \mathrm{~min}$ before the first test session, in order to make certain that they are not deprived at baseline. The later test sessions followed 2, 6, and $24 \mathrm{~h}$ of abstinence, or normal smoking. In the smoking condition, subjects were requested to smoke before coming in for each test session. In the abstinence condition, nonsmoking compliance was randomly checked by asking subjects to confirm that they had not smoked, and giving carbon monoxide expired breath tests. None of the subjects in the abstinence condition failed the CO test, a criterion of less than 10 parts $\mathrm{CO}$ per million being required (West $e t$ al., 1989).

\section{Assessment measures}

Four objective performance tasks, and two subjective feeling state questionnaires were used.

Letter cancellation. (Williams, 1980; Parrott and Roberts, 1991; Parrott and Craig, 1992). This comprises a pencil-and-paper test of sustained visual attention. Subjects were required to scan rows of letters, and delete each instance of three target letters (e.g. TGU) with a penstroke. Time for completing the response sheet of 1350 letters, and total targets detected (maximum $=105)$, were each recorded. Twelve matched response sheets were varied across sessions.

Number vigilance. This computerized test of sustained attention, comes from the Cognitive Drug Research test battery (Wesnes et al., 1988; Van Harten et al., 1992). A randomly selected target number (0-9) was displayed on the right of a 34-cm colour monitor, while a rapid succession of number stimuli appeared in the screen centre (150 numbers/min). Subjects were required to press the YES button on a peripheral response box, each time a stimulus number matched the target. The series of numbers was balanced, with five targets for every 50 numbers, while no number appeared twice in succession. The 3-min test period generated 45 targets. Correct responses were recorded to the nearest $\mathrm{ms}$, and were defined as those occurring between 150-1000 ms after a target. If a response was not produced within this period, this counted as a miss; all other responses comprised false alarms.

Simple reaction time (Wesnes et al., 1988; van Harten et al., 1992). Subjects were required to press the YES response key, whenever the word YES appeared on the monitor screen. Fifty stimuli were presented with a random inter-stimulus between 1 and $3.5 \mathrm{~s}$. Statistical outliers were excluded from the calculation of average response times, while the number of outliers was also recorded.

Choice reaction time (Wesnes et al., 1988; van Harten et al., 1992). Subjects pressed the YES response button to a YES stimulus on the VDU screen, and the NO button to a NO stimulus. Fifty trials of each stimulus word were presented in a random sequence, with a random inter-stimulus interval between 1 and $3.5 \mathrm{~s}$. Incorrect responses were recorded; but they (and any statistical outliers), were automatically excluded from the calculation of the mean response time.

Self-rated feelings of stress, arousal, and pleasure. These were measured on the UEL smoking/mood questionnaire (Parrott, 1994, 1995a; Parrott and Garnham, unpublished). These moods reflect three primary feeling state dimensions (Matthew et al., 1990). Each mood factor was covered by two bipolar questions: stress, tense/relaxed and nervous/calm; arousal, lively/tired and alert/ drowsy; pleasure, contented/irritated and satisfied/ 
dissatisfied. Responses were scored on a 5-point bipolar scale: strongly-slightly-neither-slightlystrongly. Each question generated a response between $0-4$, while the overall 9-point score ranged from $0-8$.

The Addiction Research Unit (ARU) nicotine withdrawal questionnaire (West et al., 1989). This covered feelings of depression, irritability, energy, restlessness, hunger, poor concentration, and urge to smoke. The original 5-point response format (extremely - very-somewhat-slightly-not-at-all), was extended to 9 points, by the inclusion of four intermediate response positions. The aim of this procedure was to make the ARU and UEL mood scales equivalent in the number of response choices.

Heart rate. This was recorded using a Tunturi meter attached to the ear lobe (Parrott and Winder, 1989). Resting heart rate was recorded at three predetermined time points prior to testing. Testing heart rate was similarly recorded at three points during the performance test cycle. Overall means were scored.

\section{Experimental design}

Each subject was tested under both conditions, with the test order counterbalanced (smoking/ deprived; deprived/smoking). The baseline test session commenced at around 10 am (range 9-11 am) while later sessions were held after $2 \mathrm{~h}, 6 \mathrm{~h}$, and $24 \mathrm{~h}$ (the next morning). No restrictions on everyday activities were made, although each subject was tested on a weekday when they were already coming to the University. Each subject acted as their own control, so the two test days should have been similar in terms of general patterns of occupational activity. Testing was in an individual cubicle, with the experimenter also present. Subjects were fully trained on the performance tasks beforehand. This comprised an initial familiarization session, followed by three spaced practice sessions. The subjective feeling states were completed at 2-h intervals throughout the day, at 0,2 , $4,6,8,10,12$ and $24 \mathrm{~h}$.

\section{Data analysis}

The data were analyzed by split-plot ANOVA with three factors: drug (smoking, deprived), time $(0-24 \mathrm{~h}$ ), and order of testing (smoking/deprived, deprived/smoking). The SPSS-pc package was also used to calculate drug effects within each time period.

\section{RESULTS}

Group mean values are shown in Tables 1 and 2, while the ANOVA findings are summarized in Table 3. Selected measures are also presented graphically: letter cancellation (Figure 1), number vigilance (Figure 2), and several subjective feeling states (Figure 3). The characteristics of these regular smokers were broadly similar to those in other studies (West and Russell, 1985; Parrott, 1994), with Smoking Motivation Questionnaire profiles as follows: psychological image $0.4 \pm 0.7$; hand/mouth activity $4.5 \pm 3.3$; indulgent $6.0 \pm 3.2$ sedative $6.7 \pm 2.7$; stimulant $4.9 \pm 3.8$; addictive $10.3 \pm 4.0$, and automatic $1.5 \pm 1.9$.

Letter cancellation target detection was significantly affected by drug $(P<0.01)$, and drug $x$ time interaction $(P<0.001$; Table 3$)$. Baseline detection rates were similar for both conditions,

Table 1. Group means for the task performance and physiological measures

\begin{tabular}{|c|c|c|c|c|c|c|c|c|}
\hline & \multicolumn{4}{|c|}{ Normal smoking } & \multicolumn{4}{|c|}{ Smoking abstinence } \\
\hline & Baseline & $2 \mathrm{~h}$ & $6 \mathrm{~h}$ & $24 \mathrm{~h}$ & Baseline & $2 \mathrm{~h}$ & $6 \mathrm{~h}$ & $24 \mathrm{~h}$ \\
\hline Heart rate resting (bpm) & 79.9 & 79.5 & $80 \cdot 9$ & $78 \cdot 8$ & $85 \cdot 7$ & $75 \cdot 7$ & $72 \cdot 2$ & $69 \cdot 1$ \\
\hline Heart rate testing (bpm) & 86.4 & $87 \cdot 7$ & $84 \cdot 5$ & $87 \cdot 6$ & $91 \cdot 0$ & $84 \cdot 0$ & 81.6 & 76.4 \\
\hline Letter cancellation total hits & $87 \cdot 7$ & 88.7 & 89.6 & $90 \cdot 8$ & $88 \cdot 1$ & 84.6 & 80.0 & 81.8 \\
\hline Letter cancellation resp. time (s) & 357 & 338 & 352 & 386 & 370 & 369 & 411 & 400 \\
\hline Digit vigilance percentage hits & 96.4 & $98 \cdot 0$ & $98 \cdot 5$ & $97 \cdot 2$ & 97.6 & 95.9 & 96.3 & 96.7 \\
\hline Digit vigilance response time (ms) & 414 & 404 & 406 & 419 & 410 & 422 & 423 & 412 \\
\hline Digit vigilance false alarms & 0.6 & 0.5 & 0.3 & 0.5 & 0.5 & 0.3 & 0.4 & 0.4 \\
\hline Simple reaction time (ms) & 257 & 255 & 257 & 260 & 259 & 263 & 275 & 259 \\
\hline Choice reaction time (ms) & 416 & 404 & 404 & 414 & 422 & 418 & 423 & 429 \\
\hline Choice reaction time $\%$ accuracy & $98 \cdot 1$ & 97.9 & 96.9 & 97.4 & 97.6 & 97.4 & 97.9 & 96.8 \\
\hline
\end{tabular}



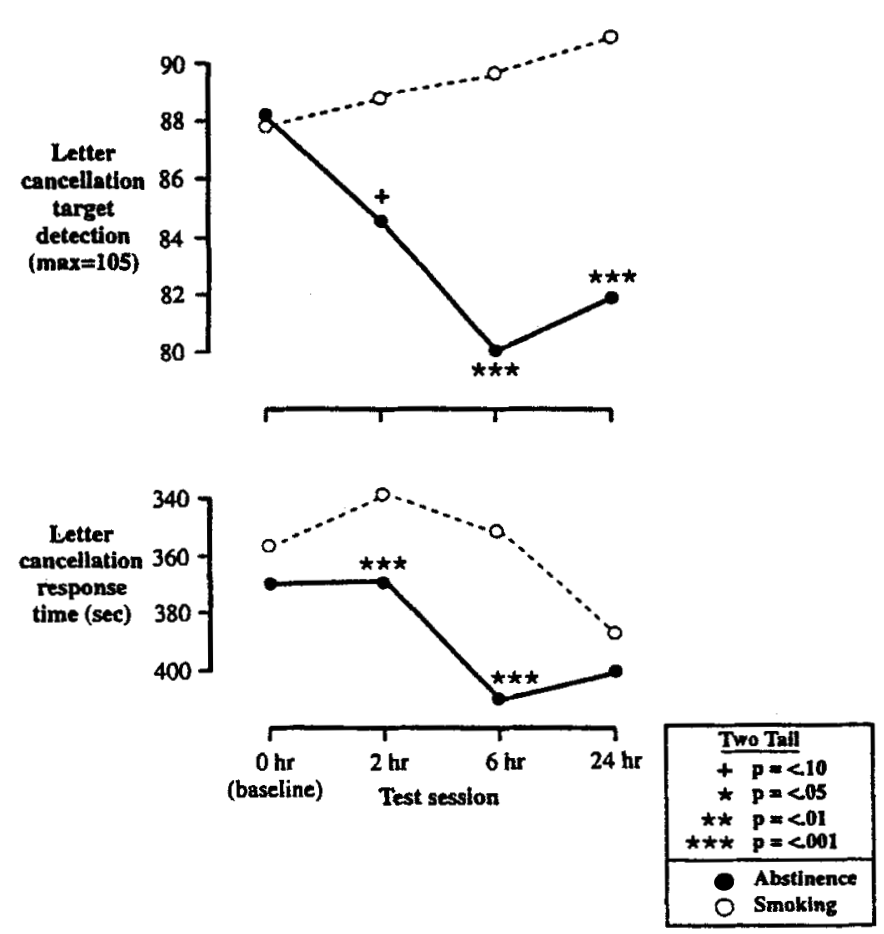

Figure 1. Letter cancellation task performance under cigarette smoking and abstinence

but became comparatively impaired under abstinence. Significantly lower target detection rates were evident after 2,6 , and $24 \mathrm{~h}$ of smoking deprivation (Figure 1, Tables 1, 3). Letter cancellation response times showed a similar pattern, with significant ANOVA drug $(P<0.01)$, $(p<0.001)$, and drug $\times$ time $(P<0.05)$ effects (Table 3). Compared to normal smoking, response times were comparatively longer under abstinence, with significantly poorer performance at the 2-and 6-h sessions, although not after $24 \mathrm{~h}$ (Figure 1).

On the number vigilance task, similar performance trends were generally evident, with higher rates of target detection and faster responses under smoking than abstinence (Figure 2). The ANOVA

Table 2. Group means for the self-rating questionnaires

\begin{tabular}{|c|c|c|c|c|c|c|c|c|c|c|c|c|c|c|c|c|}
\hline & \multicolumn{8}{|c|}{ Normal smoking } & \multicolumn{8}{|c|}{ Smoking abstinence } \\
\hline & Baseline & $2 \mathrm{~h}$ & $4 \mathrm{~h}$ & $6 h$ & & $10 \mathrm{~h}$ & $12 \mathrm{~h}$ & $24 \mathrm{~h}$ & Baseline & $2 \mathrm{~h}$ & $4 \mathrm{~h}$ & $6 \mathrm{~h}$ & & $10 \mathrm{~h}$ & $12 \mathrm{~h}$ & $24 \mathrm{~h}$ \\
\hline $\begin{array}{l}\text { ARU scales } \\
\text { Depression } \\
\text { Irritability } \\
\text { Energy } \\
\text { Restlessness } \\
\text { Hunger } \\
\text { Poor concentration } \\
\text { Urge to smoke }\end{array}$ & $\begin{array}{l}0.5 \\
0.8 \\
2.4 \\
1.7 \\
2.1 \\
2.2 \\
2.7\end{array}$ & $\begin{array}{l}0.9 \\
1.3 \\
2.4 \\
1.9 \\
3.0 \\
2.3 \\
2 \cdot 6\end{array}$ & $\begin{array}{l}0.5 \\
1.1 \\
2.2 \\
1.9 \\
2.4 \\
2 \cdot 3 \\
2 \cdot 5\end{array}$ & $\begin{array}{l}0.5 \\
1.2 \\
2.1 \\
1.8 \\
1.9 \\
2.5 \\
2.7\end{array}$ & $\begin{array}{l}0.7 \\
1.0 \\
2.4 \\
1.6 \\
1 \cdot 7 \\
2 \cdot 1 \\
3 \cdot 5\end{array}$ & $\begin{array}{l}0.8 \\
1.6 \\
2.2 \\
1.7 \\
1.9 \\
2.1 \\
3.5\end{array}$ & $\begin{array}{l}0.9 \\
1.6 \\
1.5 \\
1.5 \\
1.8 \\
2.9 \\
3.3\end{array}$ & $\begin{array}{l}0.5 \\
1.2 \\
2 \cdot 3 \\
1 \cdot 5 \\
2 \cdot 3 \\
2.4 \\
3.0\end{array}$ & $\begin{array}{l}1.1 \\
1.2 \\
2 \cdot 1 \\
1.5 \\
2.4 \\
2.7 \\
3.3\end{array}$ & $\begin{array}{l}1 \cdot 1 \\
1 \cdot 5 \\
2 \cdot 2 \\
2 \cdot 3 \\
2 \cdot 9 \\
3 \cdot 0 \\
3 \cdot 2\end{array}$ & $\begin{array}{l}1 \cdot 3 \\
2 \cdot 2 \\
2 \cdot 1 \\
2 \cdot 8 \\
2 \cdot 4 \\
3 \cdot 3 \\
4 \cdot 7\end{array}$ & $\begin{array}{l}1 \cdot 7 \\
3 \cdot 4 \\
2 \cdot 1 \\
3 \cdot 4 \\
2 \cdot 7 \\
4 \cdot 7 \\
5 \cdot 4\end{array}$ & $\begin{array}{l}2 \cdot 2 \\
3 \cdot 0 \\
2 \cdot 3 \\
3 \cdot 6 \\
3 \cdot 5 \\
4 \cdot 4 \\
5 \cdot 7\end{array}$ & $\begin{array}{l}2.5 \\
3.9 \\
2.2 \\
3.7 \\
2.9 \\
3.9 \\
5.9\end{array}$ & $\begin{array}{l}2.1 \\
3.7 \\
1.7 \\
3.0 \\
2.5 \\
4.0 \\
5.6\end{array}$ & $\begin{array}{l}1.4 \\
2.8 \\
2.3 \\
2.7 \\
3.1 \\
3.7 \\
5.2\end{array}$ \\
\hline $\begin{array}{l}\text { UEL scales } \\
\text { Stress } \\
\text { Arousal } \\
\text { Pleasure }\end{array}$ & $\begin{array}{l}2 \cdot 5 \\
3 \cdot 1 \\
4 \cdot 7\end{array}$ & $\begin{array}{l}3.0 \\
4.0 \\
4.0\end{array}$ & $\begin{array}{l}2.8 \\
3.9 \\
4.4\end{array}$ & $\begin{array}{l}3.0 \\
3.4 \\
4.2\end{array}$ & $\begin{array}{l}3 \cdot 1 \\
4 \cdot 2 \\
4 \cdot 3\end{array}$ & $\begin{array}{l}2.9 \\
3.4 \\
4.5\end{array}$ & $\begin{array}{l}2.6 \\
2.3 \\
4.2\end{array}$ & $\begin{array}{l}3.4 \\
3.0 \\
4.4\end{array}$ & $\begin{array}{l}3.9 \\
3.0 \\
3.8\end{array}$ & $\begin{array}{l}3.6 \\
3.2 \\
3.6\end{array}$ & $\begin{array}{l}3.7 \\
2.7 \\
3.2\end{array}$ & $\begin{array}{l}3.8 \\
3.2 \\
2.6\end{array}$ & $\begin{array}{l}4.2 \\
3.0 \\
2.6\end{array}$ & $\begin{array}{l}4.7 \\
3.0 \\
2.3\end{array}$ & $\begin{array}{l}3.9 \\
3.0 \\
2.4\end{array}$ & $\begin{array}{l}3.7 \\
2.9 \\
3.5\end{array}$ \\
\hline
\end{tabular}


CIGARETTE SMOKING AND ABSTINENCE

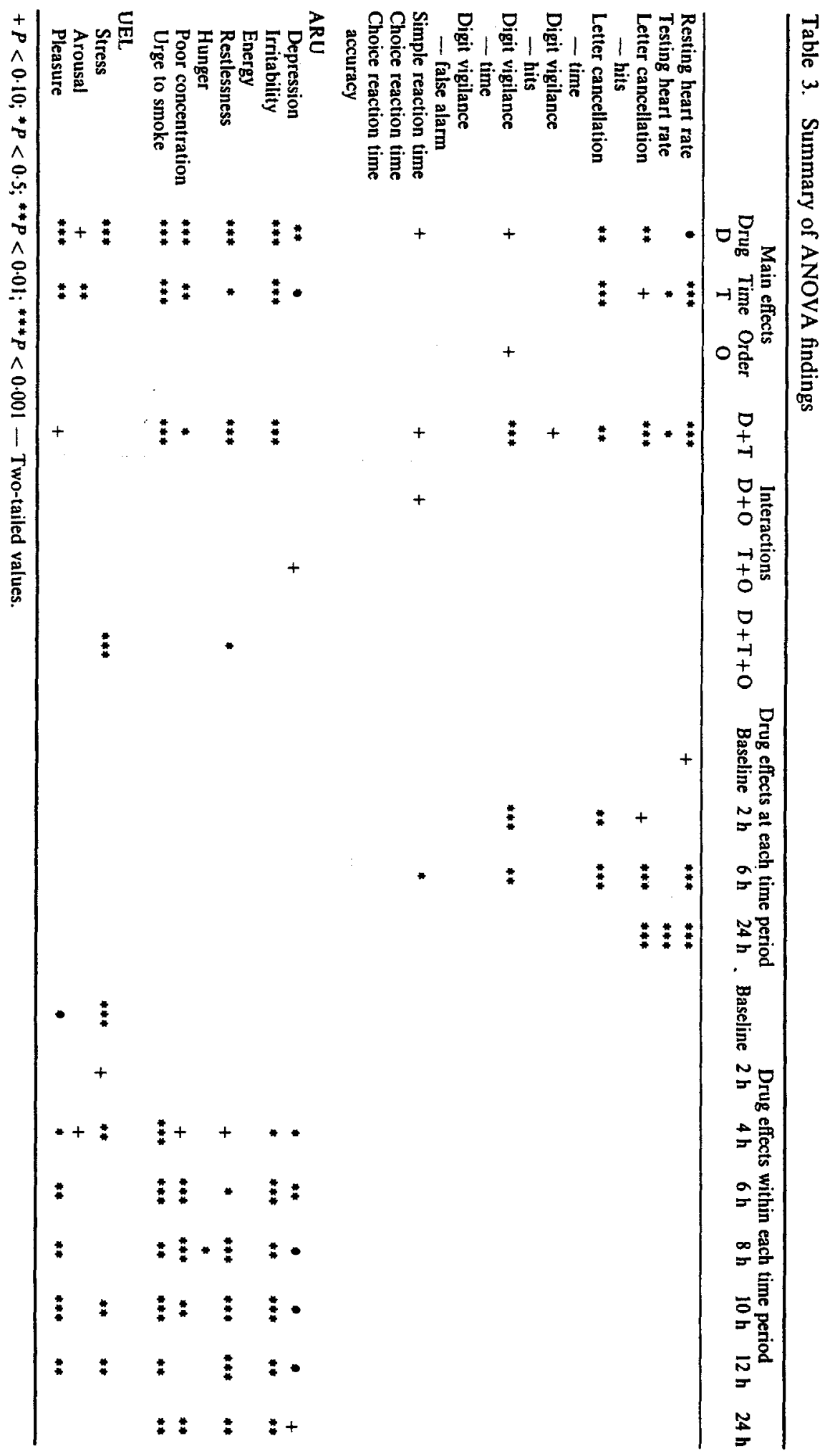



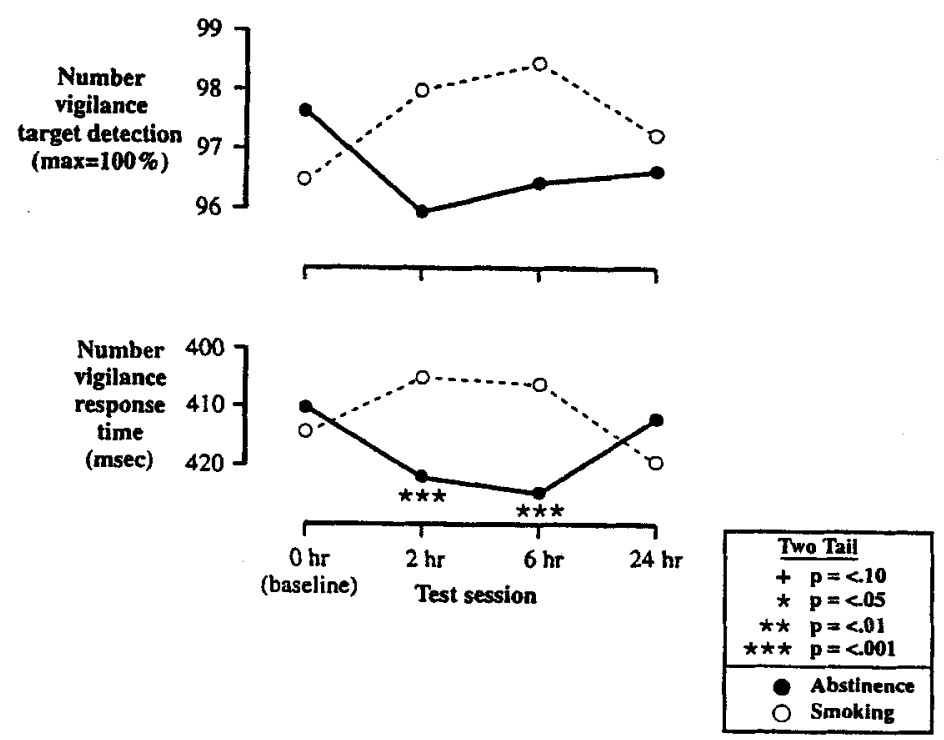

Figure 2. Number vigilance task performance under cigarette smoking and abstinence

drug $\times$ time interaction for response times was significant $(P<0.001)$, with significantly slower responses after 2 and $6 \mathrm{~h}$ of abstinence, although not after $24 \mathrm{~h}$ (Figure 2, Table 3). Number vigilance target detections showed a similar general trend, although only the drug $\times$ time interaction approached significance $(P<0.10$, two-tail; Table 3 ). It should be noted that baseline detection rates were slightly higher pre-abstinence than presmoking (Figure 2). Thus although performance tended to improve under smoking, and deteriorate under deprivation, all drug condition comparisons were non-significant (Figure 2).

Resting heart rate was significantly affected by drug $(P<0.05)$, time $(P<0.001)$, and drug $\times$ time interaction $(P<0.001$; Table 3$)$. Baseline heart rate values were generally maintained under smoking, but became reduced under deprivation. Again it should be noted that there was a borderline difference between conditions at baseline $(P<0.10$; Table 3$)$, which meant that the magnitude of all subsequent deprivation effects was slightly underestimated. Nevertheless, significant differences were evident after 6 and $24 \mathrm{~h}$ of abstinence (Table 3), while a non-significant decrease was evident at the 2-h session. Similar findings occurred with heart rates during testing (Figure 3). With simple reaction time, all three ANOVA terms were statistically borderline $(P<0.10$; Table 3$)$; response times were also significantly slower after $6 \mathrm{~h}$ of deprivation $(P<0.05$; Table 1$)$. On the choice reaction time task, none of the ANOVA effects was significant (Tables 1, 3).

With the ARU smoking withdrawal questionnaire, five of the seven scales showed significant ANOVA effects: feelings of depression, irritability, restlessness, poor concentration, and urge to smoke (Table 2). Significant mood impairments were evident after $4 \mathrm{~h}$ of smoking deprivation, and continued at the later sessions, with the greatest decrements after 8-12 h of abstinence (Figure 3, Table 3). The two other ARU questions: feelings of hunger and energy, generated no significant ANOVA effects, although there was a tendency for increased hunger ratings under abstinence (particularly after $8 \mathrm{~h}$ - around 6 pm or mealtime; Table 2). On the UEL mood questionnaire, feelings of pleasure were generally higher after smoking than abstinence, with significant differences evident after 4-12 h. Pleasure ratings remained fairly constant over time during smoking, but deteriorated over the day during abstinence (Table 2). Feelings of arousal varied significantly over time $(P<0.05$, and were non-significantly higher under smoking than deprivation $(p<0 \cdot 10$, two tail; Tables 2, 3). Feelings of stress demonstrated a significant drug effect $(P<0.001)$, and a threeway interaction (drug $\times$ time $\times$ order, $P<0.001$; Table 3). Feelings of stress also differed significantly at baseline, which complicates further 

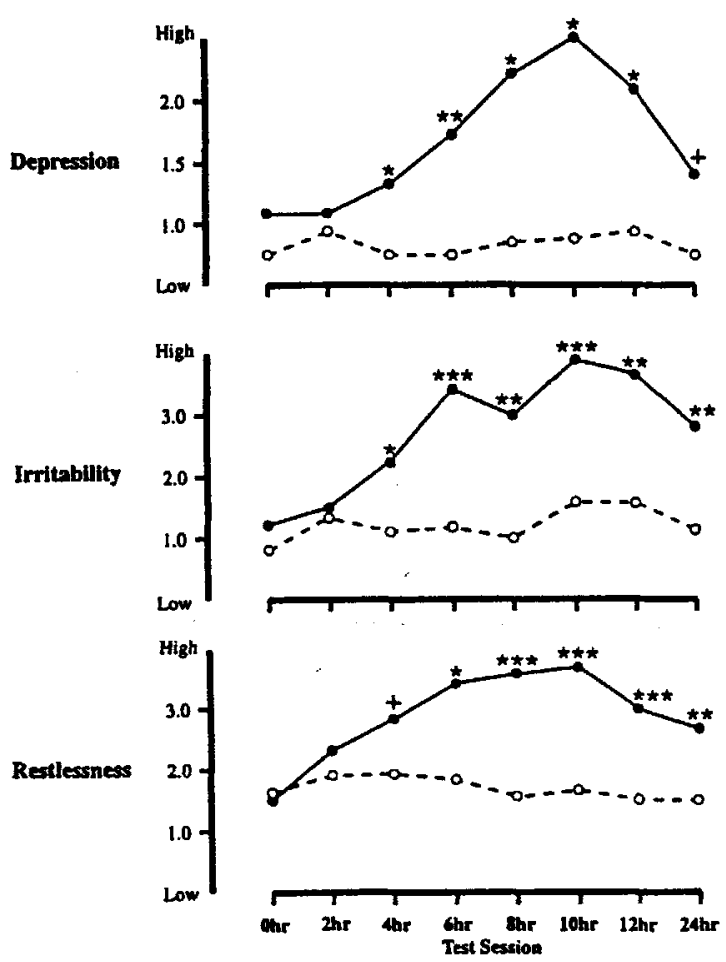
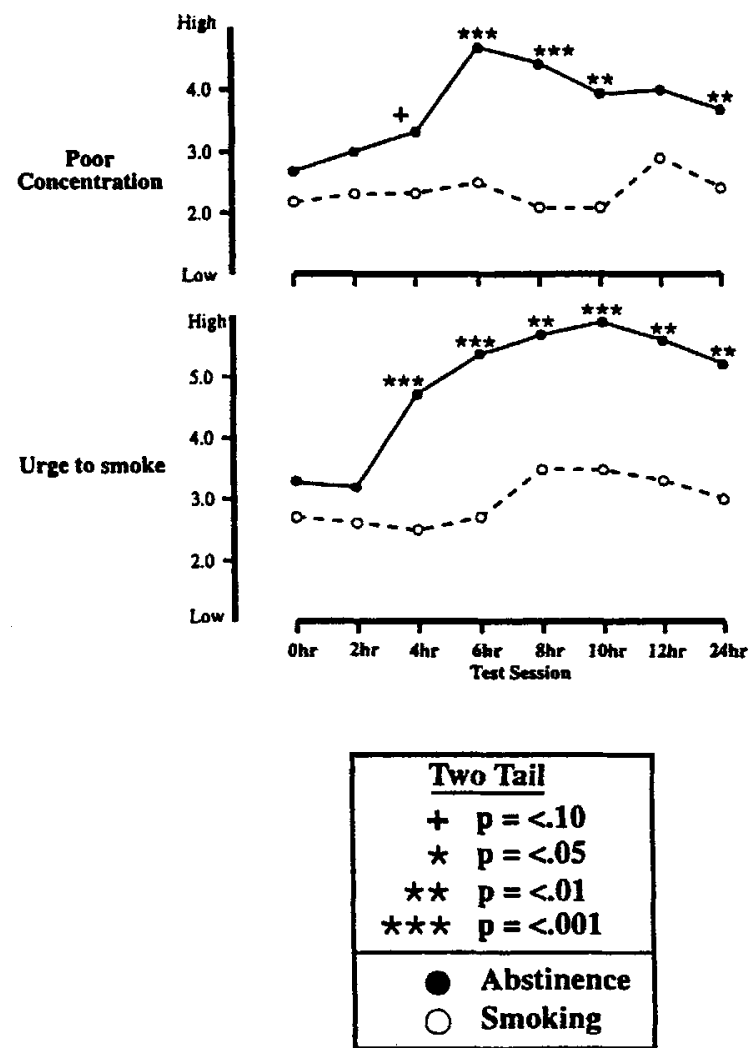

Figure 3. Feelings states over $24 \mathrm{~h}$ of cigarette smoking and abstinence

interpretation (Tables 2, 3); nevertheless, stress ratings tended to remain low during smoking, and high during abstinence (Table 2).

\section{DISCUSSION}

'Many smokers experience a range of adverse effects when they abstain from cigarettes. These include craving, increased irritability, depression, restlessness, hunger, and difficulty concentrating' (West and Russell, 1988, p. 563). These withdrawal symptoms were confirmed here, with abstinence leading to significant feelings of restlessness, depression, irritability, poor concentration, and increased urges to smoke (Figure 3). These findings agree not only with previous studies of cigarette smokers (Shiffman and Jarvik, 1976; Stizer and Gross, 1988; West et al., 1989), but also with abstinence in regular tobacco chewers, and nicotine gum users (West and Russell, 1985; Keenan et al., 1989). They therefore agree with the broader conclusion that cigarette abstinence in smokers, comprises just one form of nicotine depletion (Surgeon General, 1988; Hughes et al., 1990).

Subjective withdrawal symptoms have been noted over a range of smoking cessation periods: 2-week (Shiffman and Jarvik, 1976), 4-week (West et al., 1989), 10-week (Stizer and Gross, 1988), and 26-week periods (Hughes, 1992). They have also been noted in experimental withdrawal studies, where abstinence (generally for 1 day), is compared with an equivalent period of normal tobacco use (West and Russell, 1985, 1988; Keenan et al., 1989; see Hughes et al., 1990, p.325). These latter studies have generally monitored feelings at a single time point (generally $24 \mathrm{~h}$ ), so currently there is little data on the time course of nicotine withdrawal symptoms during the first few hours of abstinence (West et al., 1989; Foulds, 1994).

The present study found no significant mood changes at the $2 \mathrm{~h}$ session (Figure 3, Table 2). However, after $4 \mathrm{~h}$ of withdrawal, various feeling 
states were significantly altered, with increased feelings of depression, irritability, stress, low pleasure, and urges to smoke, and borderline increases in feelings of restlessness, poor concentration, and low arousal (Figure 3, Table 2). These deleterious moods generally increased at the later sessions, so that between 4 and $24 \mathrm{~h}$ of abstinence, a wide range of abstinence symptoms was evident (Figure 3). Furthermore, although the 2-h data were non-significant, several moods showed a trend towards impairment (Figure 3). Mood reversals have previously been documented within the first hour of abstinence (Perkins et al., 1992; Warburton, 1992; Parrott, 1994), but considerable individual variation in these mood changes has also been noted (Parrott, 1994, pp. 393-394). Different smokers may therefore develop abstinence symptoms at different rates, and this may have contributed to the non-significant group trends at the 2 -h session. There was also a slight trend for smokers to report poorer moods at the 2-h session (Figure 3). Indeed, both groups showed subtle patterns of mood change over the day, possibly in response to environmental events such as meals, work/test demands, or the promise of rest and relaxation in the evening. Mood states are generally sensitive to various environmental factors and altered expectations (Thayer, 1989).

Smoking abstinence can affect not only feeling states, but also task performance. Active smokers generally display higher performance than deprived smokers, on various measures of sustained attention: rapid visual information processing, the Mackworth clock test, and letter cancellation (Williams, 1980; Wesnes and Warburton, 1983; Revell, 1988; Hasenfrantz et al., 1989; Parrott and Craig, 1992; Wesnes and Parrott, 1992). However as with the subjective mood data, there is little data on their time course (Foulds, 1994). In the present study, letter cancellation was significantly impaired at the 2-h and 6-h sessions, while digit vigilance demonstrated a broadly similar pattern (Figures 1, 2). This decrement in sustained attention ability cannot be explained as a speed/accuracy tradeoff, since detection accuracy and response were impaired in parallel (Table 1). Task performance was only assessed four times each condition, and future studies should sample a wider range of time periods. This could be facilitated through the use of portable actigraphs, or hand-held computerized test systems.

Abstinence symptoms at the 24-h session held in the morning, were generally less marked than during the afternoon/evening the previous day. This was evident with several mood and performance variables, although it was not present with the physiological heart rate data (Tables $1-3$, Figures 1-3). There seems to be three possible explanations for this circadian effect. Firstly, deprivation effects may build up afresh each day. Smokers start the morning with a degree of overnight nicotine depletion, but this increases over the day if they remain abstinent. Empirical support for this explanation comes from Schneider and Jarvik (1984), who monitored mood states during the morning, afternoon, and evening, over 4 days of abstinence. The highest withdrawal ratings were found during the evenings, while the lowest occurred on the mornings each day (Figure 1 in Schneider and Jarvik, 1984). A second explanation is that at the beginning of the day, all smokers are suffering from overnight nicotine depletion. Thus any difference between experimental and control groups will be lowest during the morning (since both groups are somewhat deprived). The third explanation is that it reflects an experimental design artefact. Deprived subjects knew that they would be able to smoke on completion of the $24 \mathrm{~h}$ session (i.e. on leaving the building), and this may have acted as an incentive for faster responding and better moods.

It is difficult to decide between these three explanations. The pharmacokinetics and pharmacodynamics of nicotine provide some support for the first two models (Russell, 1989; Benowitz, 1990), while indirect support for the third comes from Snyder et al. (1989). They monitored task performance over 10 days of withdrawal, and found peak performance decrements after 24$48 \mathrm{~h}$ of abstinence. Unfortunately they did not have a control group of normal smokers, so that time of day (circadian), and learning (repetition) effects, were confounded with drug (abstinence) effects. Thus their findings do not provide clear empirical evidence on the development of abstinence symptoms over time. Nevertheless, no significant decrements were evident at their final (10 day) session, following which smoking was allowed, agreeing with the third explanation noted above.

The present 24-h data can be discussed in conjunction with Hughes (1992), who monitored withdrawal over $2,4,7,14,30,90$, and 180 days post-cessation. This enables the time course for smoking withdrawal symptoms to be broadly outlined. Hughes (1992) found that anxiety, 
irritability, restlessness, difficulty concentrating, and a composite withdrawal score, were all highest after 2 days of abstinence, then lessened in severity over subsequent sessions. Overall therefore, abstinence symptoms seem to develop within the first few hours, peak during the first few days, then decline over subsequent weeks (Figures 1-3; Snyder et al., 1989; Hughes, 1992). Furthermore, the timescale for objective and subjective withdrawal symptoms also seem to be fairly similar. It should be noted that the present findings question the concept of the 'minimally deprived' smoker. A number of studies have tested smokers who have abstained from smoking for only a few hours. These have been termed 'minimally deprived', and any mood/ performance changes interpreted as genuine psychological gains. The current findings question that interpretation, and suggest instead that these changes may reflect the reversal of abstinence effects (either partially or wholly).

The opposing psychological effects of smoking and abstinence, have been summarized by two contrasting models. The nicotine resource model, suggests that smoking generates genuine $\operatorname{mood} /$ performance gains, while abstinence reflects a return to baseline (Warburton, 1992). The deprivation reversal model, suggests that abstinence generates deleterious levels of mood and task performance, while smoking simply restores normal levels of psychological functioning (Parrott, 1994, 1995a,b). The present data do not allow these alternative explanations to be distinguished; their aim was simply to document the time profile for abstinence symptoms. In order to compare these two explanatory models, equivalent data from non-smoker controls is required, so that is the focus for our present study (Parrott and Garnham, unpublished). However, several further topics also need to be investigated. Firstly, the degree of individual variation in the development of abstinence symptoms, since differences in initial onset, maximal severity, and subsequent decline, are each likely. A second topic is the circadian profile of smoking withdrawal symptoms; this would help answer the question (raised earlier), of whether abstinence symptoms build-up afresh each day. Thirdly, the mood/performance effects of smoking, need to be directly related to the mood/ performance effects of abstinence. This could answer the question of whether there is a direct link between the psychological functions served by smoking, and the withdrawal symptoms experienced during cessation.

\section{ACKNOWLEDGEMENTS}

Natasha Garnham was funded by the Higher Education Research Funding Council.

\section{REFERENCES}

Benowitz, N. L. (1990). Pharmacokinetic considerations in understanding nicotine dependence. In: The Biology of Nicotine Dependence, Ciba Foundation Report, 152. Wiley, Chichester.

Folkard, S. (1983). Diurnal variation. In: Stress and Fatigue in Human Performance, Hockey, R. (ed.), Wiley, Chichester, pp. 245-272.

Foulds, J. (1994). Detrimental effects of nicotine on mood? Addiction, 89, 136-137.

Hasenfrantz, M., Michel, C., Nil, R. and Battig, K. (1989). Can smoking increase attention in rapid visual processing during noise? Electrocortical, physiological and behavioural effects. Psychopharmacology, 98. 75-80.

Hughes, J. R. (1992). Tobacco withdrawal in selfquitters. Journal of Consulting and Clinical Psychology, 60, 689-697.

Hughes, J. R., Higgins, S. T. and Hatsukami D. (1990). Effects of abstinence from tobacco. In: Research Advances in Alcohol and Drug Problems, Vol. 10, Kowslowski, L. T., Annis, H. M., et al. (Eds), Plenum, New York, pp. 317-398.

Keenan, R. M., Hatsukami, D. K. and Anton, D. J. (1989). The effects of short-term tobacco deprivation on performance. Psychopharmacology, 98, 126-130.

Matthews, G., Jones, D. M. and Chamberlain, A. G. (1990). Refining the measurement of mood: the UWIST mood adjective checklist. British Journal of Psychology, 81, 17-42.

Parrott, A. C. (1994). Individual differences in stress and arousal during cigarette smoking. Psychopharmacology, 115, 389-396.

Parrott, A. C. (1995a). Stress modulation over the day in cigarette smokers. Addiction, 90, 233-244.

Parrott, A. C. (1995b). Smoking cessation leads to reduced stress, but why? International Journal of the Addictions, 30, 1509-1516.

Parrott, A. C. and Craig, D. (1992). Cigarette smoking and nicotine gum $(0,2$, and $4 \mathrm{mg})$ : effects upon four visual attention tasks. Neuropsychobiology, 25, 34-43.

Parrott, A. C. and Garnham, N. J. Mood and cognitive task performance profiles of cigarette smokers, deprived smokers, and nonsmokers. Unpublished.

Parrott, A. C. and Roberts, G. (1991). Smoking deprivation and cigarette reinstatement: effects upon visual attention. Journal of Psychopharmacology, 5, 402-407.

Parrott, A. C. and Winder, G. (1989). Nicotine chewing gum $(2 \mathrm{mg}, 4 \mathrm{mg}$ ) and cigarette smoking: comparative effects upon vigilance and heart rate. Psychopharma$\operatorname{colog} y, 97,257-261$. 
Perkins, K. A., Grobe, J. E., Fonte, C. and Breus, M. (1992). Paradoxical effects of smoking on subjective stress versus cardiovascular arousal in males and females. Pharmacology Biochemistry and Behavior, 42, 301-311.

Revell, A. (1988). Smoking and performance: a puff-bypuff analysis. Psychopharmacology, 96, 563-565.

Russell, M. A. H. (1989). Subjective and behavioural effects of nicotine in humans: some sources of individual variation. Progress in Brain Research, 79, 289-302.

Schneider, N. G. and Jarvik, M. E. (1984). Time course of smoking withdrawal symptoms as a function of nicotine replacement. Psychopharmacology, 82, 143-144.

Shiffman, S. and Jarvik, M. (1976). Smoking nicotine withdrawal symptoms in two weeks of abstinence. Psychopharmacology, 50, 35-39.

Snyder, F. R., Davis, F. C. and Henningfield, J. E. (1989). The tobacco withdrawal syndrome: performance decrements assessed on a computerised test battery. Drug and Alcohol Dependence, 23, 259-266.

Stitzer, M. and Gross, J. (1988). Smoking relapse: the role of pharmacological and behavioural factors. In: Nicotine Replacement: A Critical Evaluation, Pomerleau, O.F. and Pomerleau, C. S. (Eds), Liss, New York, pp. 163-184.

Surgeon General (1988). The Health Consequences of Smoking: Nicotine Addiction. US Government Printing Office, Washington DC, USA.

Thayer, R. E. (1989). The Biopsychology of Mood and Arousal. Oxford University Press, Oxford.
Warburton, D. M. (1992). Smoking within reason. Journal of Smoking-Related Disorders, 3, 55-59.

Wesnes, K. and Parrott, A. C. (1992). Smoking, nicotine and human performance. In: Handbook of Human Performance, Vol. 2, Smith, A. and Jones, D. M. (Eds), Academic Press, London, pp. 127-167.

Wesnes, K. and Warburton, D. M. (1983). Smoking, nicotine and human performance. Pharmacology and Therapeutics, 21, 189-208.

Wesnes, K., Simpson, P. M. and Kidd, A. G. (1988). An investigation of the range of cognitive impairments induced by scopolamine $0.6 \mathrm{mg}$. Human Psychopharmacology, 3, 27-43.

West, R., Hajek, P. and Belcher, M. (1989). Time course of cigarette withdrawal symptoms while using nicotine gum. Psychopharmacology, 99, 143-145.

West, R. and Russell, M. A. H. (1985). Pre-abstinence smoke intake and smoking motivation as predictors of severity of cigarette withdrawal symptoms. Psychopharmacology, 83, 334-336.

West, R. and Russell, M. A. H. (1988). Loss of acute nicotine tolerance and severity of cigarette withdrawal. Psychopharmacology, 94, 563-565.

Williams, G. D. (1980). Effect of cigarette smoking on immediate memory and performance. British Journal of Psychology, 71, 83-90.

Van Harten, J., Sevens, L., Raghoebar, M., Holland, R., Wesnes, K. and Cournot, A. (1992). Fluoxamine does not interact with alcohol nor potentiate alcoholrelated impairment of cognitive function. Clinical Pharmacology and Therapeutics, 52, 427-435. 